\title{
Infusing Critical Thinking Skills into Argumentative Writing: A Study of Chinese College English Learners
}

\author{
Chunxia $\mathrm{Lu}^{1}$ \\ ${ }^{1}$ Yancheng Normal University, China \\ Correspondence: Chunxia Lu, School of Foreign Languages, Yancheng Normal University, Yancheng, Jiangsu, \\ China. E-mail: classforyc@163.com
}

Received: July 28, 2021

Accepted: September 3, 2021

Online Published: September 19, 2021

doi:10.5539/ells.v11n4p8

URL: https://doi.org/10.5539/ells.v11n4p8

\begin{abstract}
Argumentative writing plays an important role in higher education with college students needing to know how to compose persuasive arguments for academic and career purposes. While writing an argumentative essay, Chinese college students not only face the challenges of the activity itself but also the difficulties of writing in a foreign language. To facilitate their argumentative writing, a revised six-element argumentative model based on Toulmin's framework infused with critical thinking skills was taught to 30 students in an English course at a Chinese Teacher-training University. Using an argumentative essay test in a pre- and post-test design, it was found that the students' holistic argumentative writing ability significantly improved after the intervention. However, the students' ability to rebut remained weak.
\end{abstract}

Keywords: argumentative writing, critical thinking, Chinese college English learners

\section{Introduction}

The role of argumentative writing in higher education is well established. It helps "advance students' understanding of scientific concepts, ability to communicate, and scientific literacy" (Aguirre, Chen, Terada, \& Techawitthayachinda, 2020, p. 2045) and "sharpen students' sense of meaning and significance to an issue" (Andrews, 2009, p. 1). The ability to argue is a natural expectation in higher education courses (ibid.). In China, the context of the present study, an English learner is required to be capable of producing argumentative essays according to China's Standards of English Language Ability (2018). Advanced learners especially, need to articulate clear viewpoints and convincing arguments on topical social issues.

However, argumentative writing is a difficult skill to acquire. Writing, as a language skill, requires learners to organize their ideas into written texts, which entails writers' intellectual ability, cognitive strategies, and motivation as well as linguistic, pragmatic and social competencies. These qualities make writing a complex that needs "systematic and well-ordered thinking" (Hasani, 2016). The complexity of writing is related to the genre of argumentative writing. Argumentative writing is not only a linguistic activity, but also a social and rational activity as well as a means of resolving conflicts over controversial issues (Van Eemerren \& Grootendorst, 2004). Furthermore, compared with the oral mode of argumentation, written argumentation is more complicated, as it requires a particular well-organized discourse structure, while no particular structure is needed for the oral mode (Freedman \& Pringle, 1984).

Given the dual complexity of argumentation and writing, it is the most challenging kind of writing compared with other genres (Ferretti et al., 2007). Producing a complete argument that covers the necessary elements for argumentation, i.e., including sufficient evidence and providing a reasonable response to the counterarguments is a challenging task for many students (Ferretti et al., 2000). Students also need to manage rhetorical concerns such as organization, structure and the development of ideas during the writing processes (Wei, 2001).

In the Chinese context, due to the complicated nature of argumentative writing, college English learners' performance is less than satisfactory. Lu and Swatevacharkul (2021) reported that Chinese college students' English argumentative writing is vague in expression, monotonous in structures, words and ideas and illogical. $\mathrm{Xu}$ (2021) analyzed the narrative and argumentative writing processes of 60 Chinese second-year college students via Inputlog 7.0, and found they were likely to transfer Chinese argumentative structure into their English writing processes resulting in feeble and ineffective argumentation and conclusions. The ideas contained 
within were also limited as they would repeat similar information instead of generating new ideas.

Meanwhile, argumentative writing is reported to be closely related to critical thinking (CT) ability, which lays a foundation for effective argumentation. Pei, Zheng, Zhang and Liu (2017) found that Chinese college EFL learners with high levels of critical thinking skills outperformed those with lower levels in terms of relevance, clarity, logicality, profundity and flexibility in their argumentative writing. They suggested integrating CT into EFL argumentative writing instruction. Putri (2018) also found that CT made a $48.4 \%$ contribution to Indonesian senior high school students' argumentative writing ability and suggested to promote CT into argumentative writing.

Accordingly, the present study set out to develop Chinese students' argumentative writing ability by infusing CT skills. Considering the difficulties and challenges of argumentative writing that the students are exposed to, a revised Toulmin's argumentation model based on Toulmin's framework (1958), which includes six elements (Claim, 'My side/Your side', Evidence, Warrant, Rebuttal, and Conclusion) was applied; this model provides an argumentative discourse structure with critical thinking infused into the model.

\section{Literature Review}

The term 'argue' is from the Latin word 'arguere', which means to show or to accuse. As the ancient syllogism says, "All men are mortal. Socrates is a man. Therefore, Socrates is mortal." Here, arguments comprise two premises and one conclusion. In this tradition, the key to understanding arguments is to determine whether the premises are credible enough to lead to a valid conclusion. This syllogism may be the earliest model of argumentation. In the education field, research on argumentation is mainly guided by the Toulmin (1958) model (Nussbaun, 2011).

Toulmin's model maps argumentation with six elements: data, claim, warrants, qualifiers, rebuttals and backing. Based on the Toulmin Model, Wolf, Britt and Butler (2009) made another distinction highlighting the "my side" and "your side" components. "My side" elements are those that represent the author's viewpoint plus supporting reasons, whereas the "your side" components are those that represent the arguments against the author's viewpoint (counterarguments). Considering Chinese college students' weakness in reasoning from the opposite side, $\mathrm{Lu}$ (2020) revised the six elements in the Toulmin Model into Claim, 'My side/Your side', Evidence, Warrant, Rebuttal, and Conclusion with the intention of applying it to the English argumentative writing of Chinese college students.

Various definitions of argumentative writing have been proposed. Kuhn (1991) defined argumentative writing as a process with a series of acts: making a claim, challenging a claim, supporting a claim with reasons, questioning the reasons, rebutting the reasons, and finally reaching a conclusion. Crammond (1998) described argumentative writing as a kind of writing where the writer predicts the needs of the readers, anticipates counterarguments and the questioning of their own claims. During the process, the writers must take a position to convince the readers to perform an action or to adopt a point of view (i.e., claims are sometimes called propositions) regarding a controversy since each argumentative essay argues for or against a certain claim in order to convince readers. For Nippold et al. (2005), written argumentation is a challenging communicative task that calls for sophisticated cognitive and linguistic abilities. From the writer's cognitive aspect, writers first need to identify a controversial topic and decide which side to support and then offer facts, reasons and evidence to validate and justify their arguments and rebut any counterclaims. As for the relationship between writers and readers, writers need to take readers into consideration during the whole cognitive process of argumentation, because the final purpose of written argumentation is to convince the readers and to solve the conflicts between the different sides.

The three definitions discussed above emphasize different aspects of argumentative writing. Kuhn (1991) viewed argumentative writing as a writer's individual act. Crammond (1998) brought readers into the definition. Nippold et al. (2005) defined it from the cognitive, social and linguistic aspect. Nippold's definition provides a more comprehensive understanding of argumentative writing and is the one applied in the current research. Herein, argumentative writing is viewed as a linguistic, cognitive, social and cultural act.

Writers' CT ability is reported to be closely related to the quality of an argumentative essays. Writers' CT is considered to be the foundation of argumentative writing. In an investigation of the effects of CT skills on EFL medical students' argumentative writing ability, Shahsavar (2016) found that they significantly promoted the students' argumentative writing skills after they received the CT training. Putri (2018), who studied the link between CT skills and argumentative writing skills of senior high school students, found that CT significantly promoted argumentative writing performance, providing a $48.4 \%$ contribution to the argumentative writing skills of the students. Thus, applying CT into the teaching of argumentative writing appears worthwhile. CT skills promote argumentative writing and in return argumentative writing has a positive impact on CT. However, how 
to infuse CT skills into argumentative writing instruction is unclear. Accordingly, the present study proposes detailed instruction procedures for infusing CT into argumentative writing instruction.

\section{Methodology}

\subsection{Research Question}

On average, are Chinese college EFL learners' argumentative writing abilities significantly improved after the treatment of teaching argumentative writing by infusing critical thinking skills?

\subsection{Context of the Study}

The research was undertaken in a Chinese teacher training public university in eastern China. The study took place in the Foreign Language Department which has various schools according to different language specialties. This study focused on students in the English Language School. Among the nearly 200 students in five classes in each grade, two majors in English Education, two majors in Business English and one major in Translation. The study selected the two English Education classes as the participants, because Business English majors and Translation majors have different curricula. According to the teaching curriculum of the English Education majors (See Table 1), English writing instruction lasts three semesters with one semester lasting 16 weeks. Each week has 1.5 hours of classroom instruction.

Table 1. Writing instruction curriculum for English education majors

\begin{tabular}{llll}
\hline Subjects & Semester & Duration & Contents \\
\hline Freshmen & $1^{\text {st }}$ & $\begin{array}{l}\text { No Writing Classes } \\
1.5 \text { hours per week } \\
\text { (16 weeks in total) }\end{array}$ & $\begin{array}{l}\text { Writing I: Introduction to English writing; Manuscript form; Punctuation; } \\
\text { Diction; Sentences; Figures of speech; Common errors; Paragraphs } \\
\text { Writing II: Criteria of a good writing; Steps in writing a composition; }\end{array}$ \\
& $2^{\text {nd }}$ & & $\begin{array}{l}\text { Wescription; Narration; Exposition; } \text { Argumentation; Assessment of writing } \\
\text { Writing III: Various letters: invitations; thank-you letters; apologies; }\end{array}$ \\
& $3^{\text {rd }}$ & & \begin{tabular}{l} 
Congratulations; resumes; notices; and so on; summaries; research reports \\
\hline
\end{tabular} \\
& $4^{\text {th }}$ & &
\end{tabular}

The writing course is open to students from Semester 2 to Semester 4. During Semester 2, manuscript form, punctuation, diction, sentences, figures of speech, common errors and paragraphs are taught. During Semester 3, different genres of argumentation are mainly taught to meet the college education requirements. During Semester 4, practical writing, such as invitations, notices and resumes is mainly taught. How to compose a summary and how to write a research report are also taught in this semester. Accordingly, argumentative writing is open to students in Semester 3.

During Semester 3, given that there are six argumentative writing elements (Claim, 'My side/Your side', Evidence, Warrant, Rebuttal, and Conclusion), one lesson focused on each argumentative element over two weeks. Accordingly, 12 weeks of classroom instruction was assigned for Toulmin's argumentative writing model. At the same time, critical thinking skills were also integrated into the six lessons to facilitate the instruction of argumentative elements.

Week 1 was allotted for the course introduction and the pre-argumentative essay test. Instruction of the revised Toulmin six-element argumentative writing model with CT skills began in the second week and lasted from Week 2 to Week 13 and each element lasted two weeks. Week 14 was allotted for the post-argumentative essay test. Week 15 and 16 were for course review. Table 2 shows the time allocation for instruction.

Table 2. Time allocation for argumentation during in the writing course semester 3

\begin{tabular}{lll}
\hline Weeks & Contents & Argumentative Writing Elements \\
\hline 1 & $-\quad$ Introduction of six-element argumentative writing model infused & \\
& $\quad$ by critical thinking skills & \\
$2-3$ & Pre-argumentative Essay Test & \\
$4-5$ & Lesson 1 & Claim \\
$6-7$ & Lesson 2 & My side/Your side \\
$8-9$ & Lesson 4 & Evidence \\
$10-11$ & Lesson 5 & Warrant \\
$12-13$ & Lesson 6 & Rebuttal \\
14 & $-\quad$ Post-argumentative Essay Test & Conclusion \\
$15-16$ & Review & \\
\hline
\end{tabular}




\subsection{Sample}

The participants, 30 English major sophomores age 18-21 of level 2 in two English education classes, were in their third semester and had been college students for one and a half years. Their English level was roughly intermediate. They were chosen because their writing course design was typical of Chinese universities. Their normal instruction included language points, four genres (i.e., description, narration, exposition, and argumentation) and finally practical writing (i.e., invitation letters, thanks letters and notices). All participants had a similar educational background: 10 years of English instruction ( 3 years in primary school, 6 years in middle school and 1 year in college).

Table 3. Characteristics of the participants

\begin{tabular}{lll}
\hline Characteristics & Count & Percentage \\
\hline Gender: & $\mathbf{3 0}$ & $\mathbf{1 0 0}$ \\
Male & 4 & 13 \\
Female & 26 & 87 \\
Age: & $\mathbf{3 0}$ & $\mathbf{1 0 0}$ \\
18 & 2 & 7 \\
19 & 19 & 63 \\
20 & 7 & 23 \\
21 & 2 & 7 \\
\hline
\end{tabular}

\subsection{Pedagogical Preparation}

In order to design six lessons, six topics were chosen because writing topics play an important role during the production of a successful argumentative essay (Grabe \& Kaplan, 1996). Only the topics suitable for arguing were chosen (see Ehrhardt, 2011). The author first found 10 topics that were attractive and controversial. Then the researcher asked the students from different classes but in the same grade as the participants to choose the most preferable ones for argumentative writing. Finally, six topics from the 10 were chosen, namely New Ways of Consumption, Paid or Unpaid, Homework Banning, Imitation \& Innovation, Artificial Intelligence and Term-time Holiday. The six topics corresponded to the instruction of six argumentative writing elements. So far six lessons were designed. Then each lesson was designed based on the pedagogical framework proposed by $\mathrm{Lu}$ and Swatevacharkul (2021), which compromises explicit instruction of CT skills and the six elements, teacher's feedback and students' reflection. Accordingly, six elements and CT were taught according to six-stage instruction framework: instruction, guided practice, independent application, transfer and elaboration, independent practice and autonomous writing. The teacher's feedback was comprised of objective grading according to the rubrics and subjective comments provided to the students. The students reflected on their learning process; for example, they described what they did, how they felt, what the difficulties were, what were the impacts on their writing process, what would they do next?

\subsection{Design of the Study}

The research tool, the pre- and post-argumentative essay test, was developed in order to measure the participants' argumentative writing ability before and after the treatment. Firstly, 10 topics suitable for college-level argumentative writing tasks were selected from a database for English majors. Then, a survey about the familiarity of each writing task was presented to other students in the same grade as the participants. The other students were required to choose the tasks they had already seen under the assumption that the main sample participants would have also seen these tasks. The motive behind doing this was to eliminate any influence that the participants' background knowledge might have brought to the research. Among the 10 tasks, one topic on eating and drinking in subways was finally chosen as the argumentative writing task for the pre- and post-argumentative writing test. The topic was then adapted to the controversial issue of whether food and drinks should be permitted on the subway. The participants were required to write about 250 to 300 words within 45 minutes in class. The word- and time-length requirement was made according to the teaching syllabus for the writing course.

To score the pre- and post-argumentative essays, the rubric from Lu and Swatevacharkul (2020) was employed (See Appendix A) with the justification that descriptive rubrics can ensure the consistency and reliability of raters (Jonsson \& Svingby, 2007). The argumentative essay test with the scoring rubrics was designed for collecting quantitative data to examine the participants' argumentative writing ability before and after the treatment. Table 4 shows the details. 
Table 4. Timeline for data collection

\begin{tabular}{lll}
\hline Weeks & Procedures & Data \\
\hline $\begin{array}{l}\text { Week 1 } \\
\text { Wefore Intervention) }\end{array}$ & Pre-argumentative Essay Test & Scores (n=30) \\
(During Intervention) & Six Lessons & \\
Week 2-Week 3 & & \\
Week 4-Week 5 & Lesson 1 New Ways of Consumption & \\
Week 6-Week 7 & Lesson 2 Paid or Unpaid & \\
Week 8-Week 9 & Lesson 3 Homework or Banning & \\
Week 10-Week 11 & Lesson 4 Imitation \& Innovation & \\
Week 12-Week 13 & Lesson 5 Artificial Intelligence & \\
Week 14 & Lesson 6 Term-time Holiday & Scores $(\mathrm{n}=30)$ \\
(After Intervention) & Post-argumentative Essay Test & \\
\hline
\end{tabular}

\section{Data Analysis and Findings}

The data from the pre- and post-argumentative essay tests were analyzed immediately after they were collected. The data analysis followed the procedures below:

Step 1: The author together with another experienced rater conducted a pilot scoring on 10 papers selected at random based on Rubrics for rating argumentative essays (See Appendix A) to ensure the reliability. Then two raters scored all the pre- and post-argumentative writing essays independently.

Step 2: A Dependent samples t-test was employed to check whether there was a significant difference between the two raters $(\mathrm{p}=0.05)$. It was found that there was no significant difference between the two raters in the pre-test $(\mathrm{t}=-1.38, \mathrm{p}=0.18)$ and in the post-test $(\mathrm{t}=-1.00, \mathrm{p}=0.33)$.

Step 3: The scores from the pre- and post-argumentative essays were statistically compared to examine whether they were significantly different.

Table 5. Students' holistic performance in the pre- and post-tests

\begin{tabular}{llllllll}
\hline Argumentative Writing Tests & N & Mean & SD & Mean Gain & t & df & Sig. (One-tailed) \\
\hline Pre-test & 30 & 14.28 & 2.78 & 5.38 & 12.16 & 29 & 0.000 \\
Post-test & 30 & 19.66 & 1.78 & & & & \\
\hline
\end{tabular}

Table 5 shows that the mean score significantly increased from $14.28(\mathrm{SD}=2.78)$ in the pre-test to 19.66 $(\mathrm{SD}=1.78)$ in the post-test $(\mathrm{t}=12.13, \mathrm{p}=0.05)$.

Step 4: To check the degree of improvement of the participants' argumentative writing ability, G*power, a statistical software developed by Erdfelder, Faul, and Buchner (1996), was applied to measure the effect size. According to Cohen's interpretation (1988), $\mathrm{d}<0.20$ means a small effect, $\mathrm{d}>0.2$ and $<0.5$ means a medium effect, and $\mathrm{d}>0.8$ means a large effect. The calculated effect size was 1.38 , which is large, indicating that the improvement degree was large and that participants' post-test scores were significantly better than that of their pre-test.

Step 5: Table 6 shows the detailed change in the participants' performance in the pre- and post-argumentative essay tests scores of the six argumentative elements: Claim, My side/Your side, Evidence, Warrant, Rebuttal, and Conclusion in the pre-test and the post-test were then analyzed. 
Table 6. Students' performance in terms of six criteria in the pre- and post-tests

\begin{tabular}{lllllllll}
\hline Criteria & $\begin{array}{l}\text { Argumentative } \\
\text { Writing Test }\end{array}$ & $\mathbf{N}$ & Mean & SD & $\begin{array}{l}\text { Mean } \\
\text { Gain }\end{array}$ & $\mathbf{t}$ & $\mathbf{f}$ & $\begin{array}{l}\text { Sig. } \\
\text { (One-tailed) }\end{array}$ \\
\hline Claim & Pre-test & 30 & 3.00 & 0.69 & 0.51 & 4.19 & 9 & 0.00 \\
& Post-test & 30 & 3.51 & 0.29 & & & & \\
My side/ & Pre-test & 30 & 2.81 & 0.70 & 0.51 & 3.77 & 29 & 0.00 \\
Your side & Post-test & 30 & 3.32 & 0.45 & & & & \\
Evidence & Pre-test & 30 & 2.73 & 0.52 & 0.68 & 6.71 & 9 & 0.00 \\
& Post-test & 30 & 3.41 & 0.28 & & & & \\
Warrant & Pre-test & 30 & 2.77 & 0.51 & 0.28 & 2.98 & 9 & 0.01 \\
& Post-test & 30 & 3.05 & 0.39 & & & & \\
Rebuttal & Pre-test & 30 & 1.29 & 0.73 & 0.50 & 3.12 & 9 & 0.00 \\
& Post-test & 30 & 1.79 & 0.70 & & & & \\
Conclusion & Pre-test & 30 & 1.68 & 0.49 & 0.61 & 5.62 & 9 & 0.00 \\
& Post-test & 30 & 2.29 & 0.46 & & & & \\
\hline
\end{tabular}

The scores from of all six categories increased significantly $(\mathrm{p}=0.05)$. The category that the students improved in most was Evidence (Mean Gain=0.68), followed by Conclusion (Mean Gain=0.61), Claim (Mean Gain=0.51) and My side/Your side (Mean Gain=0.51), Rebuttal (Mean Gain=0.50), and Warrant (Mean Gain=0.28) based on the mean gain.

The mean of Evidence in the pre-test was 2.73 and in the post-test was 3.41, which indicates that the participants' writing level regarding evidence was improved from Generally Developed (Mean=2.53, $\mathrm{SD}=0.52$ ) to Well Developed (Mean=3.41, SD=0.28). Conclusion improved from the level of Partially Developed (Mean=1.68, $\mathrm{SD}=0.49$ ) to Generally Developed (Mean=2.29, $\mathrm{SD}=0.46$ ). My side/Your side improved from the level of Generally Developed (Mean=2.81) to Well Developed $($ Mean=3.32).

For the other three categories, Claim improved but within the same range of Well Developed; the mean in the pre-test was $3.00(\mathrm{SD}=0.69)$ and the post-test was $3.51(\mathrm{SD}=0.29)$. Rebuttal improved but remained Partially Developed; the mean in the pre-test was $1.29(\mathrm{SD}=0.73)$ and in the post-test was $1.79(\mathrm{SD}=0.70)$. The smallest increase according to the mean gain was Warrant (Mean Gain=0.28), but the ability improved from the level of Generally Developed to the level of Well Developed.

\section{Discussion and Conclusions}

The findings revealed participants' argumentative writing ability as a whole improved significantly, although participants' progress in the six respective argumentative writing elements varied. In general, however, the instruction of the six elements of argumentation together with the infusion of CT appeared to be helpful for Chinese college students' argumentative writing. First, due to integration of CT skills, students learnt to analyze and evaluate the quality of reasoning. As was shown in their post-argumentative essays, more and various convincing and credible evidence was provided to support students' claims. Better quality evidence contributes to better quality warrants and rebuttals, which then help writers reach sounder conclusions.

The participants' awareness of the six-element argumentation model also led to better argumentative essays. Ferretti (2007) stated that the coverage of the elements can predict better quality argumentative essays. After the participants were taught that argumentative writing compromises six elements, they took all six elements into consideration when they wrote, especially the elements of 'your side' and 'rebuttal'. When the students took the opposite side into consideration, it is likely that 'my side' bias was diminished, which helps improve the quality of argumentative essay. At the same time, with the help of CT, they organized these elements in a more appropriate structure in order to maximize the convincing effects.

The third factor appeared to come from the use of the argumentative essay assessment rubrics. The instruction of six elements with rubrics cultivated students' awareness of the argumentative elements and ensured the students had a clear picture of how to persuade. As Andrade (2000) claimed, rubrics can support student learning and the development of sophisticated thinking skills. Thus, the six-element instruction approach together with the rubrics promoted the improvement of the participants' argumentative writing performance.

Despite the improvement of the students' whole argumentative writing ability, their ability to rebut remained only partially developed. One possible reason is related to cultural factors, because culture, writing and argumentation are always bound. Argumentation itself is a cultural phenomenon not only a linguistic one (Ferretti et al., 2019). Writers who grow up in a Confucian-oriented society deeply understand and naturally 
follow such core values as decorum, benevolence, righteousness, loyalty, faithfulness, filial piety and kindness. Under such a background, it is considered to be impolite to challenge and rebut others' opinions. Thus, it is understandable that Chinese students are not willing to argue and not used to arguing against conflicting opinions even when they are encouraged to argue in argumentative writing classes. Liu (2009) had similar findings when he investigated the impact of cultural factors on Chinese and American college students' rhetorical choices in argumentative writing discourse. In his study, Chinese students always avoided directly refuting opposing ideas mainly to maintain collective harmony. Chinese students have a more complicated interpretation of interpersonal arguing with more sensitivity to face-to-face disagreement compared with US counterparts (Xie et al., 2015). In general, Chinese students are not willing to argue with others and at the same time they do not see the necessity of argumentation in most cases because harmony can be achieved despite the differences in opinion. These cultural perceptions necessarily affect writers' argumentative processes. However, the ability to provide salient and relevant rebuttals is essential as it is a fundamental element of argumentation (Nussbaum \& Schraw, 2007). Thus, how to train Chinese college students' rebuttal ability needs further study.

This study investigated the effectiveness of the revised six-element argumentative writing model by infusing CT skills into Chinese college English learners' argumentative writing. Findings revealed that explicit instruction of six argumentation elements and critical thinking skills is helpful for Chinese college English learners' argumentative writing ability as participants made significant progress after the treatment. The significant improvement implies that the teacher's feedback and students' reflection were beneficial pedagogical tools for facilitating the teaching of argumentative writing. Despite the progress of participants' general argumentative writing ability, their ability to rebut remained relatively weak. The reason may be rooted in traditional cultural factors. The study implies that cultural factors should be taken into consideration during the training of Chinese college students' argumentative writing and that more effective training methods can be explored to cultivate the ability to rebut.

\section{Acknowledgments}

The work in this article was supported by the Philosophy and Social Science Research Fund, Educational Commission of Jiangsu Province of China (2020SJA1885).

\section{References}

Aguirre-Mendez, C., Chen, Y. C., Terada, T., \& Techawitthayachinda, R. (2020). Predicting components of argumentative writing and achievement gains in a general chemistry course for non-major college students. Journal of Chemical Education, 97(8), 2045-2056. https://doi.org/10.1021/acs.jchemed.0c00042

Ammar, A. M. I. (2016). Reflective blogfolios in the language classroom: Impact on EFL tertiary students' argumentative writing skills and ways of knowing. Advances in Language and Literary Studies, 7(5), 247-261. https://doi.org/10.7575/aiac.alls.v.7n.5p.247

Andrade, H. G. (2000). What do we mean by results? Using rubrics to promote thinking and learning. Educational Leadership, 57(5), 13-18.

Andrews, R. (2009). Argumentation in Higher Education. Springer Berlin Heidelberg. https://doi.org/10.4324/9780203872710

Ardianti, T. M., \& Bharati, D. A. (2016). Students' participation in learning argumentative writing through writing workshop. LANGUAGE CIRCLE: Journal of Language and Literature, 11(1), 67-78.

Balta, E. E. (2018). The relationships among writing skills, writing anxiety and metacognitive awareness. Journal of Education and Learning, 7(3), 233-241. https://doi.org/10.5539/jel.v7n3p233

Cohen, J. (1988). Statistical Power analysis for the behavioral sciences (2nd ed.). Hillsdale, NJ: Lawrence Earlbaum Associates.

Crammond, J. G. (1998). The uses and complexity of argument structures in expert and student persuasive writing. Written Communication, 15(2), 230-268. https://doi.org/10.1177/0741088398015002004

Ehrhardt, P. V. (2011). Critical Thinking and Writing Skills. London: Anthem Press.

Faranani, A. A. K., \& Faryabi, F. (2016). The effects of pre-task planning on Iranian EFL undergraduates' argumentative writing task performance. Journal of Recent Research in English Language Studies, 3(2), 97-116.

Ferretti, R. P., Andrews-Weckerly, S., \& Lewis, W. E. (2007). Improving the argumentative writing of students with learning disabilities: Descriptive and normative considerations. Reading \& Writing Quarterly, 23(3), 


\section{7-285. https://doi.org/10.1080/10573560701277740}

Ferretti, R. P., \& Graham, S. (2019). Argumentative writing: Theory, assessment, and instruction. Reading and Writing, 32(6), 1343-1357. https://doi.org/10.1007/s11145-019-09950-x

Ferretti, R. P., Macarthur, C. A., \& Dowdy, N. S. (2000). The effects of an elaborated goal on the persuasive writing of students with learning disabilities and their normally achieving peers. Journal of Educational Psychology, 92(4), 694-702. https://doi.org/10.1037/0022-0663.92.4.694

Freedman, A., \& Pringle, I. (1984). Why students can't write arguments. English in Education, 18(2). https://doi.org/10.1111/j.1754-8845.1984.tb00668.x

Grabe, W., \& Kaplan, R. B. (1996). Theory and Practice of Writing. New York: Addison Wesley Longman.

Hasani, A. (2016). Enhancing argumentative writing skill through contextual teaching and learning. Academic Journals, 11(16), 1573-1578.

Jonsson, A., \& Svingby, G. (2007). The use of scoring rubrics: Reliability, validity and educational consequences. Educational Research Review, 2(2), 130-144. https://doi.org/10.1016/j.edurev.2007.05.002

Kobayashi, H., \& Rinnert, C. (2008). Task response and text construction across L1 and L2 writing. Journal of Second Language Writing, 17(1), 7-29. https://doi.org/10.1016/j.jslw.2007.08.004

Kuhn, D. (1991). The Skills of Argument. Cambridge, UK: Cambridge University Press. https://doi.org/10.1017/CBO9780511571350

Liu, Y. (2009). The impact of cultural factors on Chinese and American college students' rhetorical choices in argumentative discourse: A contrastive study. Intercultural Communication Studies, 18(1), 128-142.

Lu, C. X., \& Swatevacharkul, R. (2020). A pedagogical framework for teaching Chinese college English learners' argumentative writing via infusion of critical thinking. World Journal of English Language, 11(1), 1-8. https://doi.org/10.5430/wjel.v11n1p1

Macarthur, C. A., Jennings, A., \& Philippakos, Z. A. (2019). Which linguistic features predict quality of argumentative writing for college basic writers, and how do those features change with instruction? Reading and Writing, 32, 1553-1574. https://doi.org/10.1007/s11145-018-9853-6

Nippold, M. A., Wardlonergan, J. M., \& Fanning, J. L. (2005). Persuasive writing in children, adolescents, and adults: A study of syntactic, semantic, and pragmatic development. Language Speech \& Hearing Services in Schools, 36(2), 125-138. https://doi.org/10.1044/0161-1461(2005/012)

Nussbaum, E. M. (2011). Argumentation, Dialogue Theory, and Probability Modeling: Alternative Frameworks for Argumentation Research in Education. Education Psychologist, 46(2), 84-106. https://doi.org/10.1080/00461520.2011.558816

Pei, Z. W., Zheng, C., Zhang, M., \& Liu, F. (2017). Critical thinking and argumentative writing: Inspecting the association among EFL learners in China. English Language Teaching, 10(10), 31. https://doi.org/10.5539/elt.v10n10p31

Putri, R. O. (2018). Investigating the link between critical thinking skill and argumentative writing skill: The case of Islamic Senior High School. Journal Pendidikan dan Pengajaran, 5(2), 144-128. https://doi.org/10.19109/ejpp.v5i2.2090

Shahsavar, Z. (2016). The effects of applying critical thinking skills on EFL medical students' argumentative writing. The Global eLearning Journal, 5(2), 1-5.

Tabari, M. A. (2017). Investigating the effects of planning time on the complexity of L2 argumentative writing. The Electronic Journal for English as a Second Language, 21(1), 1-24.

Toulmin, S. (1958). The use of argument. Cambridge: Cambridge University Press.

Uysal, H. H. (2012). Argumentation across L1 and L2 writing: Exploring cultural influences and transfer issues. Vigo International Journal of Applied Linguistics, 9(9), 133-156.

Van Eemeren, F. H., \& Rob, G. (2004). A Systematic Theory of Argumentation. Cambridge: Cambridge University Press. https://doi.org/10.1017/CBO9780511616389

Wei, Z. (2001). Performing argumentative writing in English: Difficulties, processes, and strategies. TESL Canada Journal, 19(1), 34. https://doi.org/10.18806/tesl.v19i1.918

Wolfe, C. R., Britt, M. A., \& Butler, J. A. (2009). Argumentation schema and the myside bias in written 
argumentation. Written Communication, 26(2), 183-209. https://doi.org/10.1177/0741088309333019

Xie, Y., Hample, D., \&Wang, X. L. (2015). A cross-cultural analysis of argument predispositions in China: Argumentativeness, verbal aggressiveness, argument frames, and personalization of conflict. Argumentation, 29, 265-284. https://doi.org/10.1007/s10503-015-9352-8

$\mathrm{Xu}, \mathrm{C}$. Q. (2021). The narrative and argumentative cognitive writing process of Chinese college English learners from the aspect of pauses. Foreign Language Education, 42(1), 35-40.

\section{Appendix A}

Rubrics for Rating Argumentative Essays (Lu \& Swatevacharkul, 2020)

\begin{tabular}{|c|c|c|}
\hline Points & Levels & Description \\
\hline 1 & $\begin{array}{l}\text { Minimally } \\
\text { Developed }\end{array}$ & $\begin{array}{l}\text { The claim is minimally clear and controversial. } \\
\text { The author's and the opponent's positions are hard to identify. } \\
\text { The evidence is minimally effective and convincing. } \\
\text { The evidence is inappropriately interpreted and fails to back up the author's side. } \\
\text { The counterarguments are minimally refuted. } \\
\text { The conclusion is minimally grounded. }\end{array}$ \\
\hline 2 & $\begin{array}{l}\text { Partially } \\
\text { Developed }\end{array}$ & $\begin{array}{l}\text { The claim is partially clear and controversial. } \\
\text { The author's and the opponent's positions are partially easy to identify. } \\
\text { The evidence is partially effective and convincing. } \\
\text { The evidence is partially interpreted to back up the author's side. } \\
\text { The counter arguments are partially refuted. } \\
\text { The conclusion is partially grounded with little credibility. }\end{array}$ \\
\hline 3 & $\begin{array}{l}\text { Generally } \\
\text { Developed }\end{array}$ & $\begin{array}{l}\text { The claim is generally clear and controversial. } \\
\text { - The author's and the opponent's positions are generally easy to identify. } \\
\text { The evidence is generally effective and convincing. } \\
\text { - The evidence is generally interpreted to back up the author's side. } \\
\text { The counterarguments are generally relevantly refuted. } \\
\text { The conclusion is generally grounded with limited credibility. }\end{array}$ \\
\hline 4 & Well Developed & $\begin{array}{l}\text { The claim is clear, controversial and well-developed. } \\
\text { - The author's and the opponent's positions are easy to identify. } \\
\text { The evidence is effective, convincing and well-developed. } \\
\text { The evidence is appropriately interpreted to well back up the author's side. } \\
\text { The counterarguments are well refuted. } \\
\text { The conclusion is well grounded with credibility. }\end{array}$ \\
\hline 5 & Highly Developed & $\begin{array}{l}\text { The claim is clear, controversial and fully developed. } \\
\text { - The author's and the opponent's positions are fully-developed and easy to identify. } \\
\text { The evidence is effective, convincing and fully developed. } \\
\text { The evidence is fully interpreted to back up the author's side. } \\
\text { The counterarguments are fully and saliently refuted. } \\
\text { The conclusion is fully grounded with high credibility. }\end{array}$ \\
\hline
\end{tabular}

\section{Copyrights}

Copyright for this article is retained by the author, with first publication rights granted to the journal.

This is an open-access article distributed under the terms and conditions of the Creative Commons Attribution license (http://creativecommons.org/licenses/by/4.0/). 